\title{
Evaluation and Empirical Analysis of Chinese Low-carbon City
}

\author{
Junwei Xing \\ CPC Liaoning Provincial Party School \\ Shenyang, Liaoning 110004, China
}

\begin{abstract}
Climate change is a global issue of major concern to the international community. The important role of cities in regional and national economic and social development based on low-carbon urban construction has become an important global initiative in many countries and regions to address climate change. It is great steps of changing patterns of development. However, what is a low-carbon city? How can we establish a measure of its development and construction? How to evaluate the comparative level of China's low-carbon cities has become the focus of attention in all aspects. This paper intends to review the basis of the relevant literature and has superficial exploration.
\end{abstract}

Keywords- Low-Carbon Cities; Evaluation; Empirical Analysis

\section{INTRODUCTION}

\section{A. Theoretical Meaning of Carbon City}

As for theoretical meaning of low-carbon development paths of the city, in recent years, scholars have actively explored and made some theoretical results. Low-carbon city is the implementation of low-carbon economy in the city, including the production of low-carbon and carbon consumption, the establishment of a virtuous cycle of sustainable energy ecosystem. Building a low carbon city must adopt sustainable modes of production and consumption patterns, control the pace of development of high-carbon industry, accelerate economic restructuring, and improve the quality of development, the introduction of lowcarbon technologies. Low-carbon city is through the development of a low-carbon economy in the city, lowcarbon technology innovation. The lifestyle changes are to minimize greenhouse gas emissions city, to shake off the past, mass production, mass consumption and mass disposal of socio-economic mode of operation, the formation of structural optimization, recycling, energy efficient economy, a healthy, economical, low-carbon lifestyles and consumption patterns, and ultimately the development of the city clean, efficient development of low-carbon and sustainable development. Low-carbon city is through the concept of consumption and lifestyle changes, which is to ensure continuous improvement of the quality of life of the premise, to help reduce carbon emissions urban development patterns and social development.

Theoretical meaning low-carbon city is continuous improvement process; scholars' theoretical connotation for low-carbon city is also an understanding and awareness of the deepening process. Although scholars have studied the method and different perspective, the definition of the theory of low-carbon city is also different connotation there is too much weight. But in the following two aspects basic agreement: First, the development of low-carbon cities cannot be at the expense of economic development, and strive to win; the second is with the developed countries, which is different from the meaning of Chinese low-carbon city. We should have its own characteristics.

\section{B. Evaluation of Low-carbon City}

Building an evaluation system for low-carbon urban development for the promotion is of great significance, it not only can provide a basis for evaluating the degree of realization of the goal of a low carbon city. It is conducive for the public to have a better understanding of low-carbon city, for the implementation of the relevant government departments, it is to provide execution analysis, and that the degree of realization of urban low-carbon development will become evidence-based evaluation. To this end, domestic research departments are all discussed. From the three aspects of economic, social and environmental, it can describe the eight large state of low-carbon city, which constructed evaluation system 23 specific indicators. Designed economic system, technological systems, and social systems, environmental systems of the four criteria layer are the main reference index layers that promulgated building eco-city index system trial.

In the comprehensive evaluation method, the domestic scholars have done many researches, which are to determine the criteria for the application of more layers by weight, to get urban low-carbon economy through the development of comprehensive evaluation index of principal component analysis. According to indicators load factor, calculated evaluation value of each subsystem, FAHP weight coefficients calculated, we can obtain comprehensive evaluation of urban low-carbon development index.

\section{The Evaluation System to BuILd A LoW- CARBON CITY}

Comprehensive survey of the evaluation index system has established in the relevant research and found that there are in practice many problems. First, the information is not easy to get, some data is difficult to get through the city with a variety of statistical bulletin Statistical Yearbook. Even if they can find the relevant departments' survey to obtain the required workload that would be enormous. Second, it is difficult to quantify indicators and specific, and some qualitative indicators need to be transformed by indirect assignment or calculation, it is difficult to ensure its credibility. Third, some of the indicators because of double counting process tedious may cause multi-linearity 
assessment, and it is not easy to effectively carry out quantitative analysis and evaluation.

In view of the above problems, according to the principles of scientific, comprehensive, systematic, hierarchical, operability and other indicators selected, this paper is on the basis reference and learning evaluation system related to home and abroad. It has combined with the city's economic and social development of specific practice, selecting identified four primary indicators of economic structure, resource output efficiency, social development, environment, ecology, and 31 secondary indicators of carbon evaluation system. See Table 1 below.

Table 1 low-carbon city evaluation system

\begin{tabular}{|c|c|c|c|c|}
\hline primitive index & No. & Second index & Unit & Index properties \\
\hline \multirow{6}{*}{$\begin{array}{l}\text { Economy } \\
\text { Structure }\end{array}$} & 1 & Per capita GDP & Yuan & Positive \\
\hline & 3 & $\begin{array}{l}\text { High-tech industry output value } \\
\text { accounted for above-scale industrial output } \\
\text { value }\end{array}$ & $\%$ & Positive \\
\hline & 4 & The proportion of high-tech exports & $\%$ & Positive \\
\hline & 5 & Industrial Value Added & $\%$ & Positive \\
\hline & 7 & New product output rate & $\%$ & Positive \\
\hline & 8 & The proportion of $\mathrm{R} \& \mathrm{D}$ activities staff & $\%$ & Positive \\
\hline \multirow{5}{*}{$\begin{array}{l}\text { Resources } \\
\text { Output } \\
\text { Efficiency }\end{array}$} & 9 & Yuan GDP energy consumption & Tce / million & Negative \\
\hline & 10 & Carbon productivity & Yuan / ton & Positive \\
\hline & 14 & Labor productivity & Thousand yuan / person & Positive \\
\hline & 15 & Investment effect coefficient & - & Positive \\
\hline & 16 & Contribution rate of total assets & $\%$ & Positive \\
\hline \multirow{7}{*}{$\begin{array}{l}\text { Social } \\
\text { Development of }\end{array}$} & 17 & Urbanization & $\%$ & Positive \\
\hline & 18 & Engel coefficient & $\%$ & Negative \\
\hline & 19 & The population density & Persons / sq km & Moderation \\
\hline & 20 & $\begin{array}{l}\text { Urban residents per capita disposable } \\
\text { income }\end{array}$ & Yuan & Positive \\
\hline & 21 & People have a public transport vehicles & Standard units / million & Positive \\
\hline & 22 & The proportion of public transport & $\%$ & Positive \\
\hline & 23 & Per capita total length of the network & $\mathrm{Km} /$ people & Positive \\
\hline \multirow{3}{*}{$\begin{array}{l}\text { Ecology } \\
\text { Environment }\end{array}$} & 29 & Per capita solid waste generation & $\mathrm{T} /$ person & Negative \\
\hline & 30 & $\begin{array}{l}\text { Environmental investment accounted } \\
\text { for the proportion of fiscal expenditure }\end{array}$ & $\%$ & Positive \\
\hline & 31 & Per capita public green area & Square & Positive \\
\hline
\end{tabular}

\section{LOW-CARBON CITY EVALUATION METHOD AND MODEL}

\section{A. Evaluation Methods}

In this paper, the principal component analysis is to strike a variable factor, which is designed to exploit the idea of dimension reduction, the indicators into a composite index of the few, and the interpolation method using standardized indicators. In this paper, the existence of positive indicators, negative indicators and indicators of moderate, standardized treatments of various types of indicators are as follows:

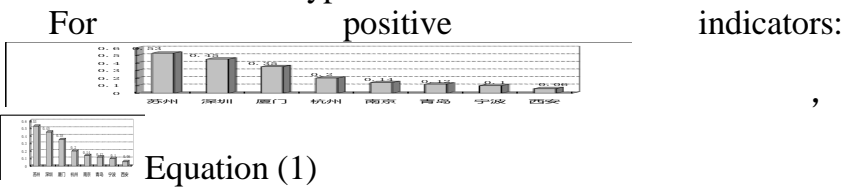




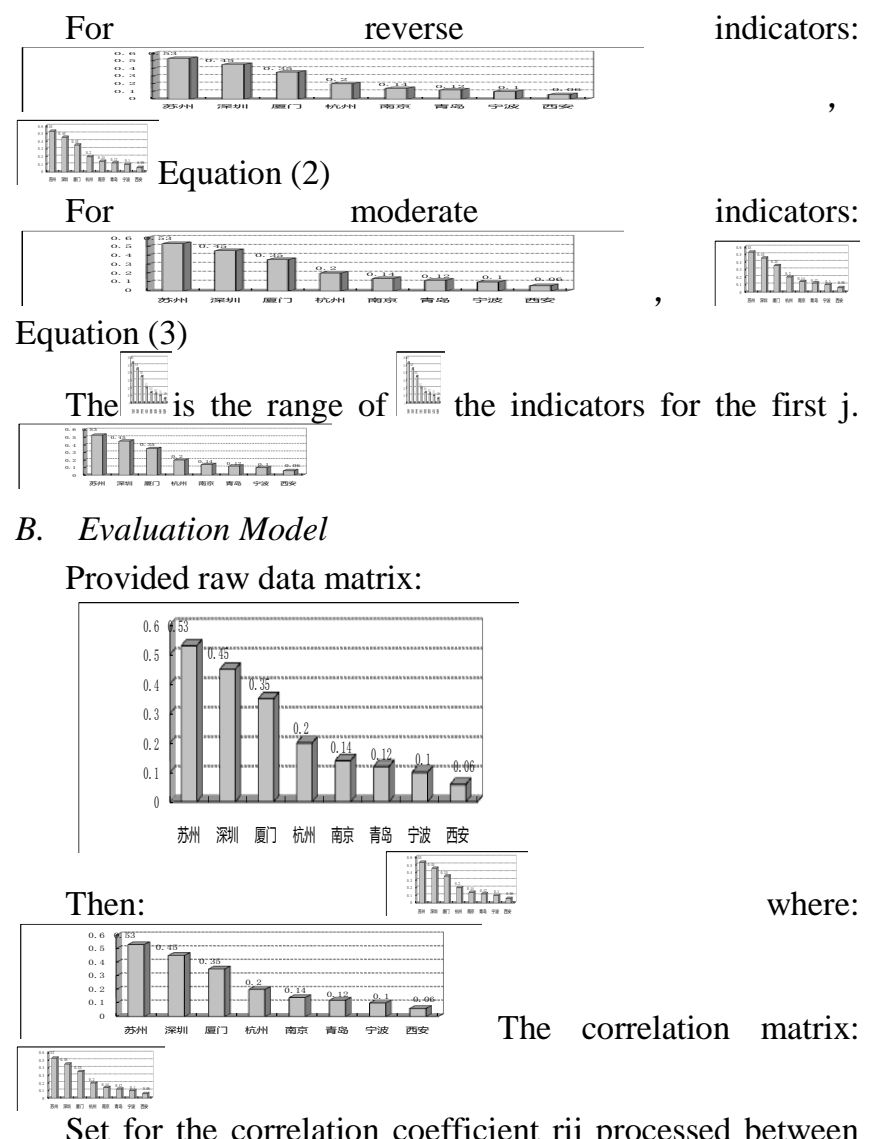
index $\mathrm{i}$ and $\mathrm{j}$ then:
standardized variables, then:
combination coefficients common factor loading matrix

In solving practical problems, generally not take $\mathrm{n}$ as principal components, but take the first $\mathrm{k}$ according to the size of the cumulative contribution rate. Contribution rate of

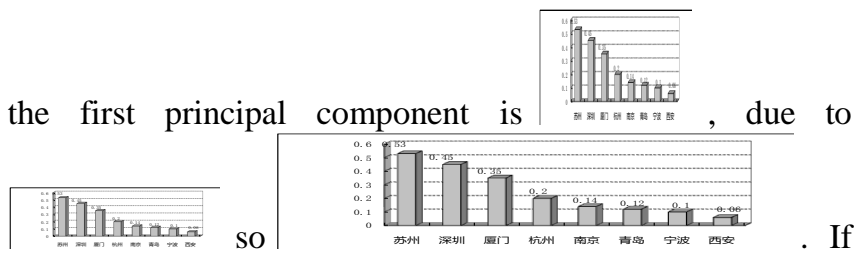
the contribution rate of the first $\mathrm{k}$ principal components of more than $85 \%$, indicating that the former principal components $\mathrm{k}$ contains all the basic measure has information.

Finally, do a linear combination of principal

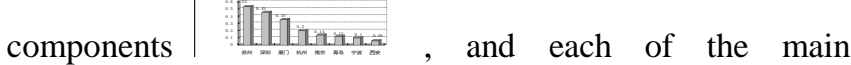
components of variance contribution rate as weights. Then we have the first $\mathrm{k}$ principal component scores were multiplied by the contribution rate variance to construct a comprehensive evaluation function: .Y is called the assessment index, calculated on the basis of each system size $\mathrm{Y}$ values to sort or classify draw level.

\section{THE EMPIRICAL ANALYSIS OF LOW-CARBON CITY EVALUATION}

This paper has the selection of Shenzhen, Suzhou, Hangzhou, Ningbo, Xi'an, Nanjing, Xiamen, Qingdao and other 8 cities as a case study to various cities Statistical Yearbook published in 2013 based on the data, according to the actual situation adjustment to obtain the revised evaluation system. Using SPSS statistical analysis software, principal component analysis and evaluation of the model to calculate for each case of city-level indicators index and the composite index scores, get the following evaluation findings.

\section{A. The Comparison of the Economic Structure Index}

Economic structure index, mainly from urban high-tech industries, services and innovation activities affects the status of the economy in the city to measure the quality and level of the city economy. From Figure 1, the sort of urban economic circumstances of each case Composite structure can be seen. Qingdao Economic Structure index was 0.12, in sixth place, away from Suzhou, Shenzhen, Xiamen and other cities there is a gap. From the basic data, Qingdao per capita GDP, the proportion of high-tech exports, $\mathrm{R} \& \mathrm{D}$ investment is in the proportion of expenditure, the total number of $R \& D$ activities in the whole society personnel is below the average of other cities, but also it need to focus on strengthening the next key point. 


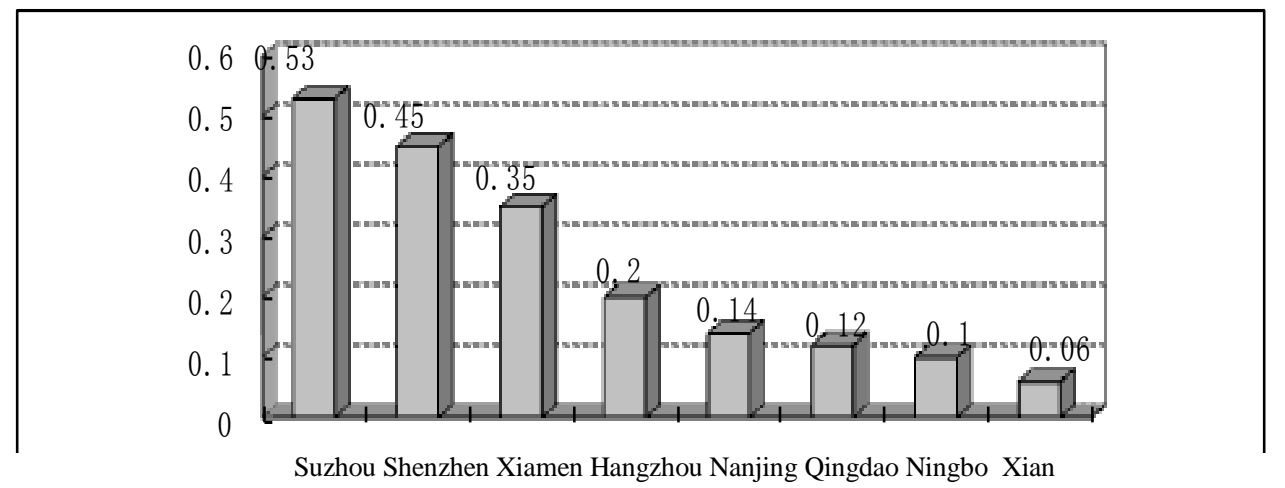

\section{B. Resource Output Efficiency Index}

Figure 1 in 2012 part of the city's economic structure index case
Resource output efficiency indicators are covering energy, land, water, and many human resources, shortage of resources constraints, and enhance their ability to support elements, improve resource output efficiency, low-carbon city development is particularly important. Figure 2 shows, the most efficient resource output index is in Hangzhou, to
0.57, ranking second is Xiamen, ranked fifth in Qingdao, resource output efficiency index of 0.29 , which is located in the lower-middle position. From the underlying data in a single index, the poor efficiency of output per unit of land, labor productivity and investment efficiency coefficient.

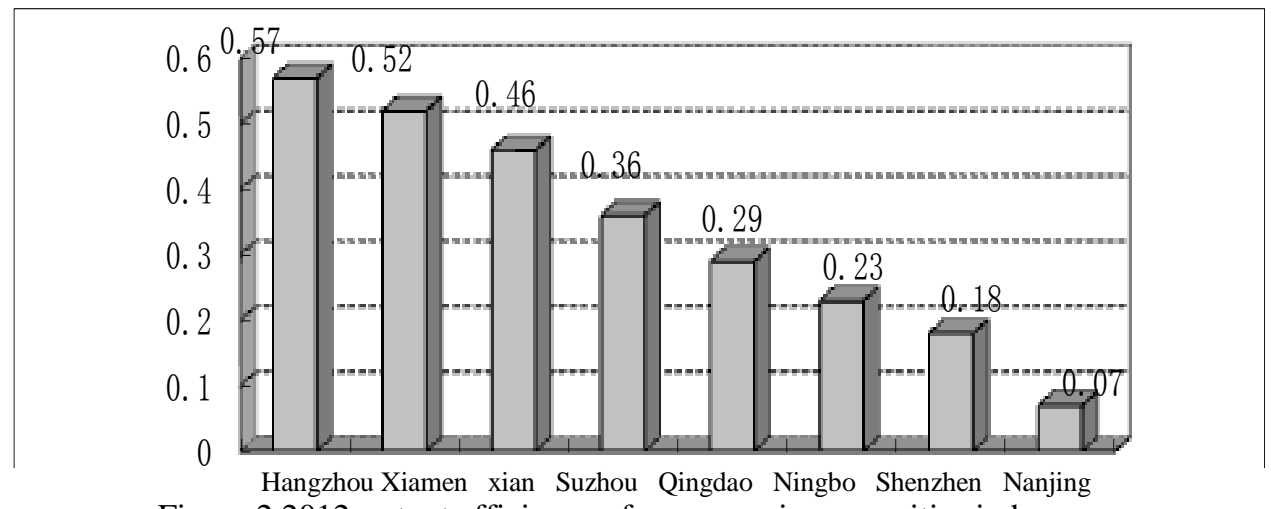

Figure 2 2012-output efficiency of resources in some cities index case

\section{Social Development Index}

Social development indicators are covering many aspects of urban construction, public transport, people's way of life, to reflect the level of urban low-carbon society. Figure 3 shows, Qingdao social development indicators is 0.11 , ranked seventh, described in terms of social development, the level of social development from Shenzhen, Nanjing, Ningbo and other cities, there are still some gaps. From a single indicator, urban residents' per capita disposable income, people have public transport vehicles, poor public transport share of the underlying data of the three indicators.

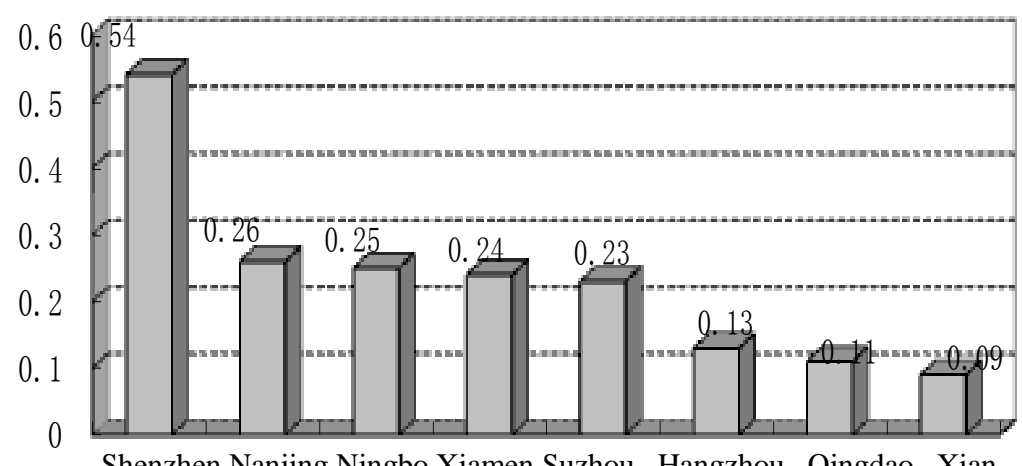

Shenzhen Nanjing Ningbo Xiamen Suzhou Hangzhou Qingdao Xian Figure 32012 in some cities and social development index case 


\section{Ecological Environment Index}

Ecological index is an important measure of low-carbon urban development, mainly reflecting the level of urban ecological environment construction in terms of air quality, waste garbage disposal, public green building. Figure 4 shows that the ecological environment Shenzhen index ranked first, followed by Hangzhou, Suzhou and Xiamen, its ecological index is of 0.30 or more, between 0.10 to 0.30 of the city of Nanjing, Qingdao and Ningbo, ranked last in the Xi'an. Qingdao poor indicators of the underlying data were mainly higher per capita carbon emissions and environmental investment accounted for a lower proportion of fiscal expenditure.

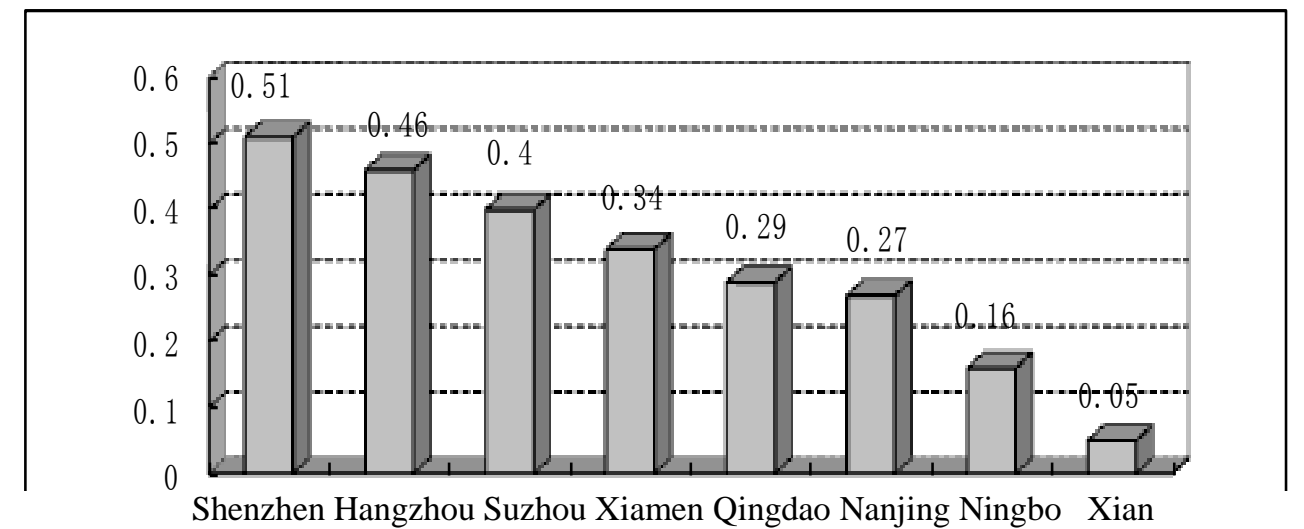

Figure 42012 part of urban ecological environment index case

\section{E. Composite Index of Low-carbon City Development}

Each case of low-carbon composite index of urban development and evaluation of specific rankings are shown in Figure 5, the construction of low-carbon city Qingdao evaluating the overall ranking is poor. Cluster analysis is based on a simple composite index that can be composite index to 0.10 and 0.30 for the boundaries of the level of low- carbon urban construction and development of each city is divided into three categories, namely, 0.30, between 0.10 to $0.30,0.10$. As Table 2 shows, Suzhou, Xiamen belong to the first category, Shenzhen the second category, Shenzhen, Hangzhou, Nanjing, Ningbo, Qingdao and Xi'an belong to the third category.

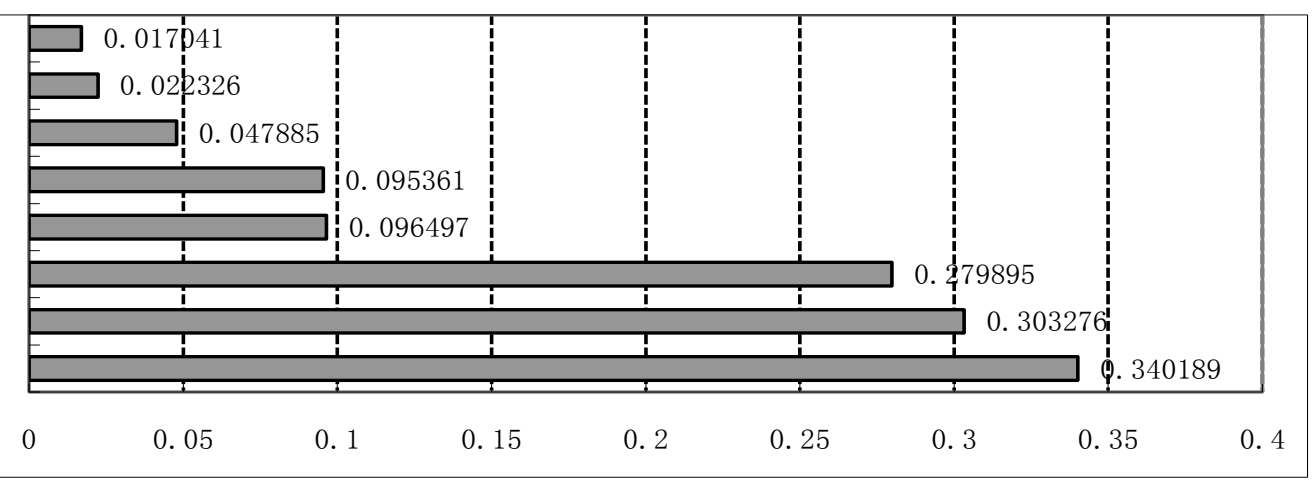

Figure 52012 parts of the city and low-carbon city evaluation index rankings

Table 2 in some cities Composite Index 2012 points level category circumstances

\begin{tabular}{|c|c|c|}
\hline $\begin{array}{c}\text { Level } \\
\text { category }\end{array}$ & City & $\begin{array}{c}\text { Composite } \\
\text { Range }\end{array}$ \\
\hline $\begin{array}{c}\text { The first } \\
\text { category }\end{array}$ & Xiamen, Suzhou & $>0.30$ \\
\hline $\begin{array}{c}\text { The second } \\
\text { category }\end{array}$ & Shenzhen & $\begin{array}{c}\text { Between } 0.10 \text { to } \\
0.30\end{array}$ \\
\hline $\begin{array}{c}\text { The third } \\
\text { category }\end{array}$ & $\begin{array}{c}\text { Hangzhou, } \\
\text { Nanjing, Ningbo, } \\
\text { Qingdao, Xi'an }\end{array}$ & $<0.10$ \\
\hline
\end{tabular}

\section{CONClusions}

Evaluation can be seen above, although the construction of low-carbon urban development has made considerable progress, there are still many issues that need further attention, mainly in the following aspects.

\section{A. Optimization and Upgrading of Industrial Structure}

Focus on developing high-tech industries and modern services, and actively cultivate and develop energy-saving and environmental protection industries, cultural and creative industries and emerging industries, such as carbon, further promote industrial upgrading and industrial layout optimization. Fully make implementation of "clean 
production" audit, and actively carry out the "green business" to create work, improve industrial wastewater, waste gas and waste heat recovery comprehensive utilization, improve resource efficiency.

\section{B. Adjust and Optimize the Energy Structure}

Accelerate the development of wind energy, solar energy, ocean energy, biomass and other low-carbon energy sources; further expand the proportion of low-carbon energy consumption. Expansion of natural gas consumption, and maximize the level of gasification and fuel supply all kinds of high quality of the city. Focus on next-generation cellulosic ethanol and hydrogen fuel, production technology of vehicle fuel, advanced energy-saving technologies, carbon capture and sequestration, renewable energy technologies such as research and development.

\section{Actively Expand Natural Carbon Sinks}

Build characteristic agriculture industry belt, use ecoorganic agriculture, and actively develop and apply "carbonbased fertilizer" to develop ecological agriculture, tourism agriculture, agricultural facilities and other modern agriculture. Implementation of straw, forest or grassland, restoration of degraded soils, take measures to reduce the use of chemical fertilizers and pesticides, and other agricultural and forestry residues utilization, protect and increase of arable and grassland carbon sinks.

\section{Promote Carbon Trading and Carbon Finance}

Actively use external resources and strength to build a low-carbon research institutions and organizations to promote, strengthen advanced research institutions in cooperation with regional and international organizations concerned in terms of technology, personnel and systems, and promote the establishment of low-carbon urban development and low cooperation mechanism carbon cities Alliance. Explore the emissions trading scheme, actively prepare timely establishment of carbon emission rights exchange.

\section{E. Guide to Promote Low-carbon Life}

Correctly guide consumer behavior, energy-saving products to adopt policies and tax incentives to encourage consumers to buy; make per capita housing space standards to guide urban residents to buy a modest area of the house, reducing heating, mining cold, heat and power and lighting needs. Advocate the election bus, cycling and walking way to travel, conserve energy, protect the environment; organize the preparation of daily consumer goods production and sales processes release carbon emissions, encourage consumers to choose less carbon products and services, research and compile the "low carbon consumer Code of Conduct "to provide consumers with low-carbon consumption guidelines.

\section{References}

[1] Xia Dianbao. Development of low-carbon economy and achieve sustainable development of the city [J]. Environmental protection, 2008,2 (13): $33 \sim 35$

[2] Xin Zhangping, Zhang Yintai. Low carbon economy and low carbon city [J]. Urban Development, 2008,15 (04): 98 to 102

[3] Fu Yun, Wang Yunlin. Path of low-carbon city development research [J] Impact of Science on Society, 2008 (02): 6-7

[4] Dai Yixin. Necessity and governance analysis of China's low carbon city development [J] China Population, Resources and Environment, 2009 (3): 15

[5] Yuan Xiaoling, Zhong Yunyun. China low-carbon city in Practice and System [J]. Low-carbon eco-city study, 2010 (05): 42 to 49

[6] Chinese Academy of Sustainable Development Research Group. China Sustainable Development Strategy Report 2009: Exploring Chinese characteristics, low-carbon path [M]. Beijing: Science Press, $2012.21 \sim 25$

[7] The Chinese Society for Urban Studies. China low-carbon eco-city development report 2010 [M]. Beijing: China Building Industry Press, $2010.109 \sim 112$

[8] Fu Yun, Liu Yijun, Wang Yunlin. Studies of low-carbon city evaluation methods and the support system [J] China Population, Resources and Environment, 2010,20 (8): 44 to 47

[9] Li Yunyan. Evaluation methods and implementation of low-carbon city approach [J]. Macroeconomic Research, 2011 (03): 51 to 53 